\title{
CARCINOMATOUS ABSCESS OF THE LUNG
}

\author{
BY \\ C. STRANG AND J. A. SIMPSON \\ From the Regional Thoracic Surgery Centre, Shotley Bridge Hospital, Newcastle-upon-Tyne
}

(RECEIVED FOR PUBLICATION MAY 29, 1952)

Lung abscess occurring in association with bronchial carcinoma often presents difficulties in diagnosis. The underlying malignant disease may easily be overlooked and valuable time may be lost, so that, when eventually the malignant nature of the condition becomes apparent, radical treatment is no longer possible. The frequency with which these cases are wrongly diagnosed as simple or tuberculous cavities has prompted us to review all the cases of neoplastic abscess seen in the Newcastle-upon-Tyne Regional Thoracic Surgery Centre over the last 12 years. From 1940 to 1951 70 cases of neoplastic abscess were admitted to the clinic, and this paper reports the results of our study of these cases and discusses the main problems encountered in diagnosis. Our criterion in selection was a radiological one, and only those cases of bronchial carcinoma presenting clear evidence of cavitation or abscess formation on a chest radiograph were included in the series.

\section{INCIDENCE}

It is not common for a bronchial carcinoma to present with the appearance of a lung abscess. The 70 cases were selected from a series of 1,930 cases of bronchial carcinoma admitted to the clinic during this period, an incidence of $3.6 \%$. The incidence of abscess formation in necropsy series of bronchial carcinoma is, not unnaturally, higher, varying from $12 \%$ to $29 \%$ (Fishberg and Rubin, 1929 ; Maxwell, 1930 ; Jaffé, 1935; Arkin and Wagner, 1936 ; Strang, 1949). Necrosis of tumour tissue is often a terminal event, and section of the lung will reveal many cases of cavitation which would not show on radiography.

When one considers the causation of lung abscess, however, bronchial carcinoma ranks fairly high as an aetiological factor. Thus, in a study of 405 cases of lung abscess, Brock (1948a) found that bronchial carcinoma was the cause in 56 cases, an incidence of $13.8 \%$, and he points out how much more important it is in causation than better-described conditions such as inhaled foreign body. Maxwell (1934) studied the necropsy find- ings in 315 cases of lung abscess and found a bronchial carcinoma in 34 of these $(10.8 \%)$.

The sex incidence shows an even more striking preponderance of males than is usually reported in bronchial carcinoma. The 70 cases were comprised of 67 males and three females. The age incidence is shown in Table I.

TABLE I

AGE INCIDENCE IN 70 CASES OF NEOPLASTIC LUNG ABSCESS

\begin{tabular}{|c|c|c|}
\hline \multicolumn{2}{|l|}{ Age } & No. of Cases \\
\hline $\begin{array}{l}30-39 \\
40-49 \\
50-59 \\
60-69 \\
70 \text { and over }\end{array}$ & $\begin{array}{l}\ldots \\
\cdots \\
\cdots \\
\ldots\end{array}$ & $\begin{array}{r}7 \\
15 \\
26 \\
21 \\
1\end{array}$ \\
\hline & otal & 70 \\
\hline
\end{tabular}

The age distribution approximates to that of bronchial carcinoma as a whole, though a higher proportion of cases occurs in the seventh decade than is usually recorded. Sixty-seven per cent occurred in the 50-69 age group. Brock found that, of his 56 patients with a lung abscess due to bronchial carcinoma, 53 were over 45 years of age.

\section{Pathology}

Abscess formation may arise in several different ways. A carcinoma occurring in a medium-sized bronchus causes partial bronchial obstruction, atelectasis, and retention infection. The inflammation may progress to destruction of lung tissue, resulting in the formation of many suppurative foci or a more localized lung abscess. Necrosis of the tumour establishes free drainage, and the destroyed tissue is coughed up. Alternatively, necrosis may develop in the centre of a tumour mass. This occurs when a rapidly growing tumour outstrips its blood supply, and the process of ulceration and liquefaction is aided by infarction and infection. The necrotic debris is then discharged into a bronchus, leaving an abscess cavity in the centre of the tumour. Sometimes so much of the tumour tissue is coughed up that only a thin carcinomatous wall is left round the 
abscess cavity, making the true malignant nature of the abscess difficult to recognize on naked-eye examination. In some of the cases reported by Fishberg and Rubin (19.29) necropsy showed the gross pathology of simple lung abscess, and it was only after a microscopic study of the cavity wall that its neoplastic origin became apparent.

In a necropsy series of 100 cases of bronchial carcinoma examined by one of us (C.S.) at the Royal Victoria Infirmary, Newcastle-upon-Tyne, there were 19 cases with abscess formation, in nine of which the cavitation was multiple. Two of these abscesses were so extensive that they replaced an entire lobe of the lung, though the size of the abscess was not necessarily related to the extent of the tumour. In one case the primary growth was not more than $1 \mathrm{~cm}$. in diameter, where it bulged into the lumen of the lower lobe bronchus, but it had produced a completely consolidated lobe with a large central abscess. The abscess contents in these cases were pus, bloodstained fluid, and necrotic tumour tissue, which, in several, was black and foul-smelling. Extension of the infection beyond the confines of the lung is a constant danger ; in seven of the cases an empyema had developed, and, in one, central extension of the infection had caused a suppurative mediastinitis.

An abscess may develop in a distant segment of the lung or in the contralateral lung due to aspiration of infected material from the primary growth. This method of origin, however, appears to be much less frequent than those already described, and was witnessed in only one case of the present series.

The development of necrosis and cavitation depends to a large extent on the histological type of the neoplasm. Specimens for histological examination were obtained in 44 of the 70 cases studied by the following means :

\begin{tabular}{|c|c|c|c|c|c|}
\hline \multirow{2}{*}{\multicolumn{4}{|c|}{$\begin{array}{l}\text { Bronchoscopic biopsy } \ldots \text {. } \\
\text { Pneumonectomy or lobectomy specimen }\end{array}$}} & & \multirow{2}{*}{21 cases } \\
\hline & & & & . & \\
\hline At thoracotomy & . & $\cdots$ & $\cdots$ & $\cdots$ & , \\
\hline Biopsy of cavily wall & . & . & . & . & , \\
\hline At necropsy & $\cdots$ & $\cdots$ & $\cdots$ & $\cdots$ & 3 ," \\
\hline Rib biopsy & . & . & . & $\cdots$ & 1 case \\
\hline Biopsy of skin nodul & . & . & $\cdots$ & $\cdots$ & ," \\
\hline & & Total & $\cdots$ & . & 44 cases \\
\hline
\end{tabular}

The histological classification of the neoplasm in these cases is shown in Table II.

\section{TABLE II}

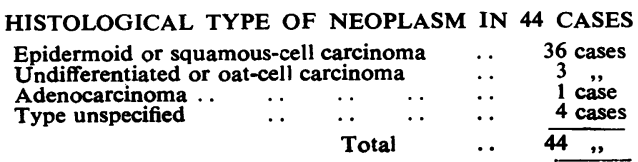

The squamous-cell type of neoplasm has a marked tendency to spread locally, and extrathoracic metastases are much less common than in the more undifferentiated tumours. It is also more prone to occur in the older patient and its progress may be relatively slow. For instance, in the 11 cases of lung cancer with a duration of more than two years reported by Goldman (1942), a squamous-cell type was found in 10 cases. The incidence of local pulmonary complications is thus higher when the tumour is of this type, and abscess formation is more liable to occur. In the series of 100 cases examined at necropsy, only 12 of the cases were of the squamous-cell type, but abscesses were present in six of these. In a similar series of necropsy cases Koletsky (1938) found 40 examples of squamous-cell carcinoma, of which 13 had broken down to form abscesses. Gray, Fryfogle, and Good (1951) reported 22 cases of malignant pulmonary abscess from the Mayo Clinic. Positive biopsies were obtained in all their cases, and 16 of these were of the squamous cell variety.

\section{Clinical Features}

The clinical manifestations of neoplastic lung abscess vary considerably. The illness may be of short duration, characterized by a high swinging temperature, sweating and shivering, cough with haemoptysis, and profuse foul sputum. At the other end of the scale, we see patients in whom the illness has taken an insidious course, with loss of weight, anorexia, and lassitude as prominent symptoms. In some patients the clinical picture is essentially that of an acute or chronic lung abscess ; in others all the symptoms and signs point to a bronchial carcinoma, and the presence of an abscess is only discovered on radiological examination.

Few diseases show greater diversity in their mode of onset than bronchial carcinoma due to the frequent occurrence of metastases in distant sites. It is noteworthy that in none of these 70 cases could the initial symptom be attributed to extrathoracic metastases. The duration of symptoms at the time of diagnosis varied from one month (five cases) to two years (two cases), with an average duration of symptoms of seven months. In one patient there were no symptoms, and the condition was picked up by a radiologist during the performance of a barium meal for duodenal ulcer. 
The initial symptom is shown in Table III.

TABLE III

INITIAL SYMPTOMS IN 70 CASES OF NEOPLASTIC LUNG ABSCESS

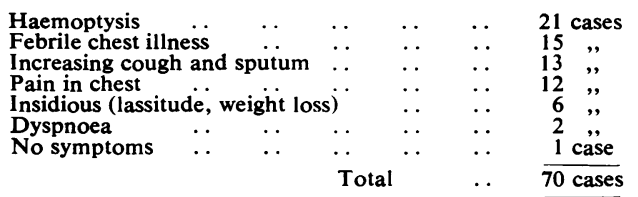

In addition to these initial symptoms, the following symptoms were recorded during the course of the illness:
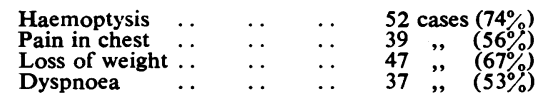

The great importance of haemoptysis in the clinical picture will be appreciated, as will the fact that only about one-fifth of the cases began with a feverish illness, such as pneumonia or influenza. Nevertheless, 48 of the patients experienced a sharp onset of symptoms (haemoptysis, fever, or pain), so those developing symptoms insidiously were in the minority.

As a means of comparison, we have also analysed the clinical features of the last 30 cases of simple chronic lung abscess admitted to the clinic. These cases fell into a younger age group (22 of them were under 50 years) and a third of the patients were women. The mode of onset in these cases is interesting when compared with the neoplastic group. In eight of them the abscess followed an operation (abdominal two, teeth extraction three, nasal one, tonsillectomy one, cervical one), in 15 it followed a pneumonic illness, and in the remaining seven there was a less dramatic onset with cough, fetid sputum, or haemoptysis. The illness was, on the average, of much shorter duration than in the neoplastic group, and the patients appeared to suffer greater constitutional disturbance. In more than twothirds of the cases, pyrexia was a prominent feature, while only one-third suffered from haemoptysis during the illness. Pain in the chest occurred in about half the cases in both neoplastic and simple groups, but in the cases of carcinoma the pain was undoubtedly more persistent and severe. Fetid sputum was commoner in the cases of simple lung abscess (Table IV).

The sputum was examined for tubercle bacilli in each of the 70 neoplastic cases at least five times, and also in some cases after concentration, by culture, and guinea-pig inoculation. The results were negative in every case, and, particularly in those cases where the radiological
TABLE IV

CLINICAL FINDINGS IN NEOPLASTIC AND SIMPLE LUNG ABSCESS

\begin{tabular}{|c|c|c|c|}
\hline & & $\begin{array}{c}\text { Neoplastic } \\
\text { Abscess }\end{array}$ & $\begin{array}{c}\text { Simple } \\
\text { Abscess }\end{array}$ \\
\hline $\begin{array}{l}\text { Average age } \\
\text { Average duration of } \\
\text { Onset with feverish } \\
\text { Haemoptysis .. } \\
\text { Pain in chest .. } \\
\text { Fetid sputum } \\
\text { Finger clubbing } \\
\text { Pyrexia in hospital } \\
\text { Anaemia } \\
\text { Leucocytosis } \\
\text { Improvement on pe }\end{array}$ & 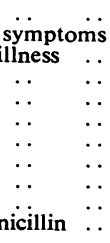 & $\begin{array}{l}55 \text { years } \\
7 \text { months } \\
20 \% \\
74 \% \\
56 \% \\
17 \% \\
59 \% \\
47 \% \\
50 \% \\
60 \% \\
7 \%\end{array}$ & $\begin{array}{l}39 \text { years } \\
2 \frac{1}{8} \text { months } \\
77 \% \\
33 \% \\
53 \% \\
47 \% \\
50 \% \\
57 \% \\
33 \% \\
40 \% \\
70 \%\end{array}$ \\
\hline
\end{tabular}

appearance closely resembled tuberculosis, this negative finding was of great assistance in diagnosis. In one case the issue was confused for a time by the finding of a bacillus in the sputum morphologically similar to $M$. tuberculosis, but repeated cultures and a guinea-pig inoculation were negative, and the diagnosis of an epidermoid carcinoma was finally established at thoracotomy. Occasionally a case of pulmonary cavitation is encountered in which a positive sputum is confidently expected yet actually proves extremely difficult to obtain. A recent case of tuberculous cavitation in a young man recalls this difficulty to mind. This patient had a left upper lobe cavity with very little surrounding infiltration and a contralateral pleural effusion. $\mathrm{He}$ was febrile and was raising 3-4 oz. of sputum daily, yet repeated sputum examinations by direct smear, using a concentration technique and culture, were negative. After many weeks of consistently negative results, a biopsy of the abscess wall was performed in the belief that it might be a malignant condition, and the cavity wall was shown to consist of tuberculous granulation tissue. Such cases, however, are rare, and one is usually able to exclude tuberculosis as the cause of pulmonary excavation by careful and repeated sputum examination.

The sputum in these cases was usually copious and purulent, and in several it was frankly fetid. The average quantity raised daily was $2-5 \mathrm{oz}$., but 13 patients raised more than an average of $5 \mathrm{oz}$. daily, while in 10 cases the average quantity was less than $2 \mathrm{oz}$. The bacteriology of the sputum indicated a mixed infection in the majority of cases. The production of these large amounts of sputum probably indicated that gross destruction of tumour tissue was taking place, and it is interesting to note that the average quantity of sputum in the simple lung abscess cases was much less and only two of them produced more than 5 oz. daily. 
Thirty-three of the cases were pyrexial while in hospital, and the majority of these ran a low-grade irregular fever. Only five cases exhibited a high swinging temperature, a type of fever which, on the other hand, was common in the cases of simple abscess. A blood count was performed in 68 of the cases. Anaemia (red blood cells below $4,000,000$ per c.mm. or haemoglobin below $80 \%$, Haldane) was found in 35 cases and a leucocytosis of over 10,000 per c.mm. in 42 cases.

The physical signs were dullness or impaired percussion note, diminished air entry, and, in the majority, moist sounds over the affected area. Only a few cases showed evidence of mediastinal or cardiac shift. The signs in the chest were of no value in differential diagnosis, but in many cases the evidence of marked loss of weight and the drawn appearance of the patient's face were strongly suggestive of malignant disease. Clubbing of the fingers occurred in 41 cases $(59 \%)$.

Five cases showed clinical evidence of extrathoracic metastases when admitted to hospital, and another seven developed metastases during the period they were under observation (hepatic three, cerebral three, extradural one, skin one, cervical glands two, sciatica two). In three of these cases the appearance of distant metastases was of assistance in making the diagnosis of carcinoma during life. Four patients developed signs of superior mediastinal venous obstruction while in hospital, or subsequently when under out-patient supervision. Fullness of the neck, dilated veins on the anterior chest wall, and a ring of dilated venules, showing as a bluish-red network on the skin along the costal margins, may provide the clue to the underlying malignancy in a lung abscess. In the same way tracheal and oesophageal compression, recurrent laryngeal nerve palsy, or infiltration of the pericardium may occur at a relatively early stage of the growth and produce clinical evidence which is of assistance in the diagnosis of neoplasm. Cerebral metastases occur with considerable frequency in these cases. In addition to the three cases mentioned, another three developed cerebral symptoms before death, which were almost certainly due to secondary deposits. The symptoms these metastases produce may be closely mimicked by those of metastatic cerebral abscess, so their appearance is not necessarily diagnostic of a carcinoma in the lung.

Although empyema was frequently encountered in the necropsy cases studied at the Royal Victoria Infirmary, Newcastle-upon-Tyne, this complication was seen in only one case of the present series. When admitted, this patient had a large abscess in the apical segment of the left lower lobe, and bronchoscopy showed a fixed stenosis of the main lower lobe bronchus. The empyema developed while he was in hospital and was treated by drainage. A subsequent bronchoscopy showed that the carcinoma had extended to the main carina and the patient died a month later.

The response to medical treatment is of considerable value in differentiating neoplastic from simple lung abscess. Sutherland and Grant (1950) believe that simple lung abscesses will respond to postural drainage and penicillin given in sufficient dosage. In the 30 cases of simple abscess selected for study, 21 resolved satisfactorily on a full medical régime, three were treated by open drainage, and six by resection. Pneumonectomy was carried out in three of these cases in the belief that the abscesses were carcinomatous. These cases deserve special consideration, for they underline the fact that even with all the diagnostic apparatus at our disposal, and the opportunity to palpate the lesion when the chest is opened, diagnosis may still be very difficult.

CASE 1 (No. 6136).-A man aged 50 noticed a bad smell in his breath. This was followed by cough and sputum sometimes yellow, sometimes brownish. He had occasional night sweats and felt ill. Examination showed a thin man, who had recently lost weight. There was no finger clubbing. Rales were heard at the left base and in the axilla. A radiograph showed an abscess $6 \mathrm{~cm}$. in diameter in the anterior segment of the left upper lobe. There was a fluid level, the wall was not very thick, but there was a good deal of surrounding pneumonitis. Bronchoscopy was normal.

The patient ran a low-grade fever; he produced $\frac{1}{2}-1$ oz. sputum daily. He had no anaemia; white cell count 9,400 per c.mm.

Treatment was postural drainage and 2,000,000 units penicillin daily. After two weeks there was no clinical improvement, and the opacity became denser on radiography. At thoracotomy a mass was felt in the anterior segment of the left upper lobe. The lung was adherent over the pericardium and the left phrenic nerve, but pneumonectomy was performed. Histology showed a simple lung abscess.

CASE 2 (No. 5304).-A man aged 50 complained of stabbing pain in the left chest followed by haemoptysis. He developed a cough, became increasingly breathless, and began to lose weight. Examination showed a healthy-looking man, with no finger clubbing, slight diminution of air entry in the left midzone, and occasional rales. Radiographs showed a shadow radiating out from the left hilum containing a clear central area. Bronchoscopy was normal. There was no pyrexia and no anaemia; white cell count 6,700 per c.mm. Penicillin, $1,000,000$ units daily, was given for a week without improvement. The appearances were highly suggestive of carcinoma, and 
thoracotomy was performed. A mass was felt in the left upper lobe, and the lung was adherent posteriorly in the paravertebral gutter. Some enlarged glands were felt around the main bronchus, but the hilum was free, and pneumonectomy was carried out. Repeated section of lung and glands showed merely a simple lung abscess, collapse, and fibrosis.

CASE 3 (No. 5724). - A man aged 55 complained of a sharp pain in the right chest seven weeks before admission. This was followed by cough, brownish sputum, and loss of weight.

Examination showed no finger clubbing, but dullness and diminished breath sounds in the right upper zone. Radiography showed a dense shadow in the posterior segment of the right upper lobe with a sharply defined lower margin suggesting collapse. The shadow contained a clear central area. Bronchoscopy showed some irregularity in the floor of the right upper lobe bronchus of which a biopsy was taken, but the histology was negative. There was no pyrexia and no anaemia; white cell count 6,000 per c.mm. At thoracotomy a hard mass was felt in the right upper lobe, and right pneumonectomy was performed in the belief that this was a bronchial carcinoma. On histological examination it proved to be a chronic lung abscess.

The response of the neoplastic abscess to penicillin and other medical measures is variable. The majority are virtually unaffected by treatment, and there is no doubt that this is a strong point in favour of the diagnosis of neoplasm. There were five patients in the series, however, who showed considerable clinical and radiological improvement following penicillin. The temperature settled, the sputum lessened, the patient felt better, and the opacities diminished in size. The crux of the problem in these cases, of course, lies in the time factor. The simple chronic lung abscess generally responds to penicillin if it is administered for sufficiently long, but if a strong suspicion of malignancy exists it is hardly justifiable to await this result, and so occasionally an unnecessary operation is performed.

The diagnosis of neoplastic abscess in these 70 cases was considered proved in 58 cases by the findings on bronchoscopy, at thoracotomy, examination of the lung after pneumonectomy, or at necropsy. Histological proof was not obtained in all of these, but naked-eye evidence of cancerous invasion was accepted. In 12 cases there was no conclusive proof, but the combination of clinical, radiological, and bronchoscopic findings was considered sufficient to warrant a diagnosis of carcinoma, e.g., paralysed vocal cord in three cases, paralysed diaphragm in two cases, broadening and fixity of the main carina in two cases, clinical evidence of distant metastases in two cases.

\section{BRONCHOSCOPIC FINDINGS}

Bronchoscopy was performed in all cases, and on the basis of the bronchoscopic findings two groups can be recognized.

TYPE 1.- In this group are the cases presenting clear evidence of a carcinoma involving a major bronchus. Some of these showed an obvious fungating growth or a whitish, irregular tumour in a main, lobar, or segmental bronchus. Others showed nodules on the mucosal surface or an appearance like granulations, and some exhibited stenosis and rigidity of a bronchus. There were 27 cases of this type, and the diagnosis was confirmed histologically in 21 of these. In four cases no biopsy was taken, but three of these were examples of a fungating carcinoma and one showed a fixed stenosis. Two cases showed distortion, narrowing, rigidity, and nodularity of an upper lobe orifice; biopsies were taken but were negative, though on naked-eye examination both were considered malignant. Most of these cases were examples of major bronchus tumours causing obstructive atelectasis and distal abscesses, and in one case the abscess appeared to arise as an aspiration infection from the primary growth.

TYPE 2.-The remaining 43 cases were probably examples of peripheral carcinomas. In most of these there were no abnormal findings except pus or redness of the bronchial tree. Ten cases, however, showed a definite bronchoscopic abnormality, though this was not regarded as indicative of a major bronchus origin for the carcinoma, e.g., bulging into the trachea or a bronchus (three cases), narrowing or distortion of a bronchus (four cases), irregularity in the floor of a bronchus (three cases). The abscess formation in these cases appeared to be caused by central necrosis in a tumour mass, and it seems that this is the commonest way for a neoplastic abscess to arise. In the 22 cases reported by Gray, Fryfogle, and Good (1951) central cavitation of the neoplastic mass had formed the abscess in 20 , and this was the mode of origin in 35 of the 56 cases recorded by Brock. When one considers that peripheral carcinomas form only 7 to $9 \%$ of all primary lung cancer (Olds and Kirklin, 1940 ; Davidson, 1948 : Strang, 1949) one sees why an abscess is a relatively rare manifestation of the condition.

An analysis of the clinical findings in the two types of case shows no striking differences. The duration of symptoms was similar. In Type 1 cases, lassitude, weight loss, and gradual increase in cough and sputum were the commonest modes of onset, and haemoptysis was less common as an 


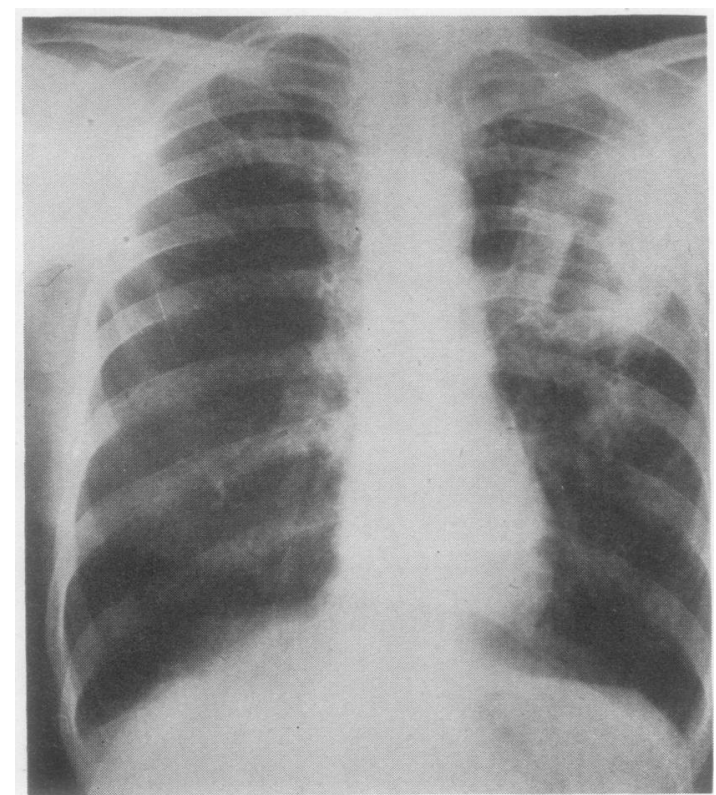

FIG 1.-Radiograph showing cavitating neoplasm $7.5 \mathrm{~cm} . \times 9 \mathrm{~cm}$. situated in the posterior segment of the left upper lobe. The patient had haemoptysis, dyspnoea, and loss of weight for 16 months. Bronchoscopy was normal. Left pneumonectomy was performed.

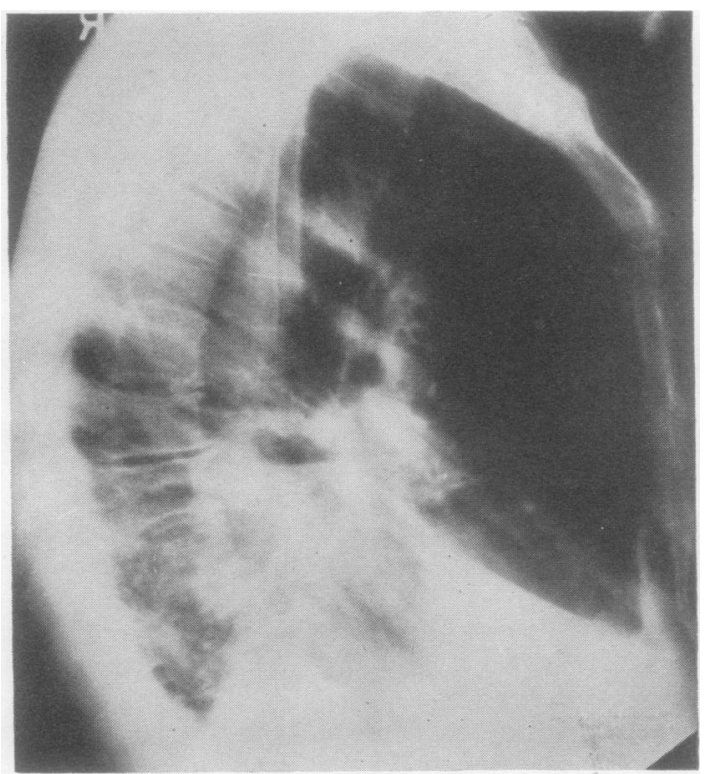

FIG. 3-Right lateral radiograph showing collapse of the right lower lobe and an abscess near the hilum. Bronchoscopy showed foul pus in the right main bronchus, but no neoplasm. At necropsy the right lower lobe was found to be infiltrated by epidermoid carcinoma.

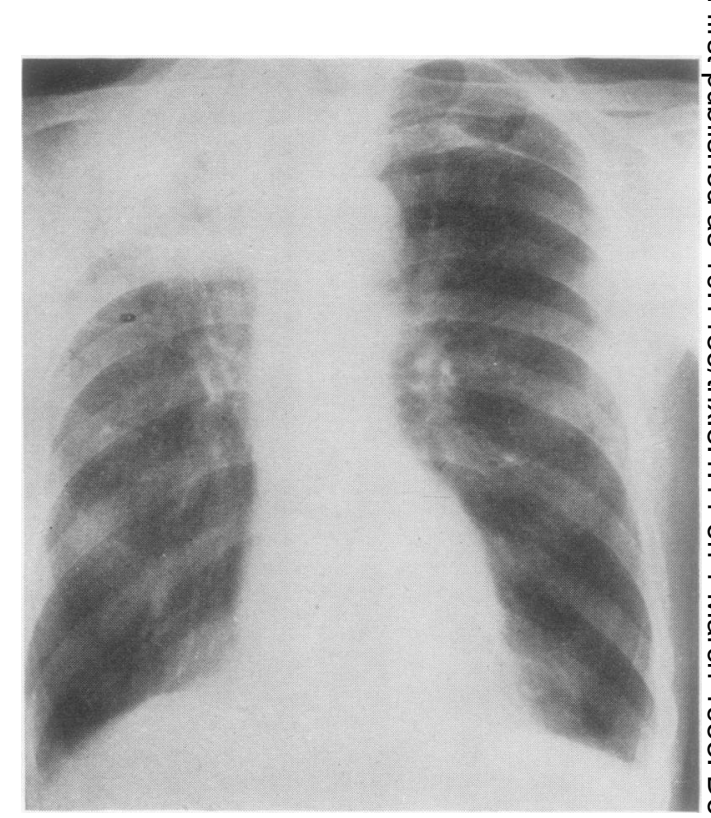

FIG. 2.-Radiograph showing abscess $7 \mathrm{~cm} . \times 5 \mathrm{~cm}$. in the posterior segment of the right upper lobe. The patient had haemoptysis, dyspnoea, and loss of weight for one month. Bronchoscopy showed irregularity in the floor of the right upper lobe bronchus. Biopsy was negative.

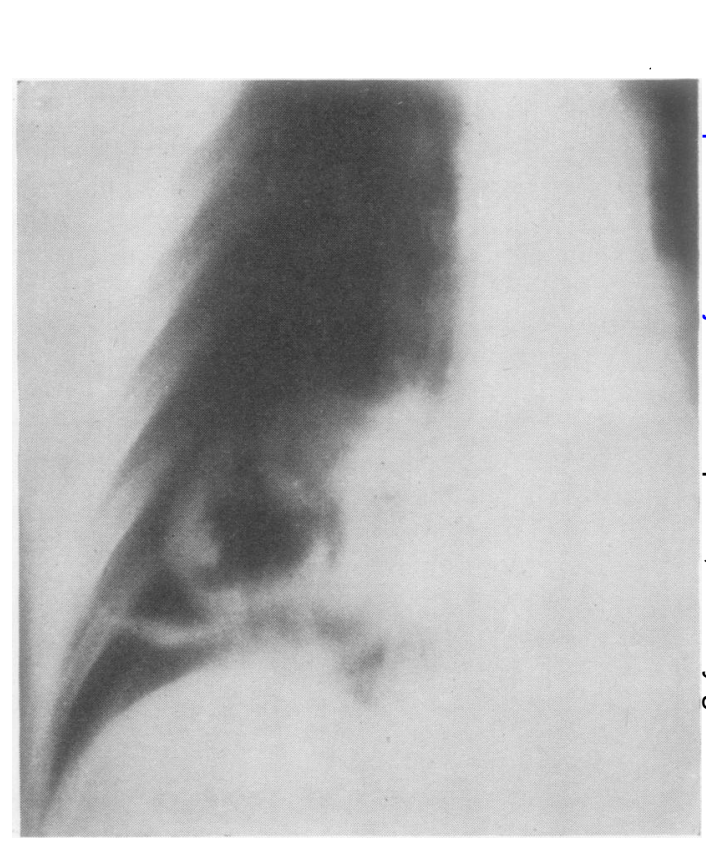

FIG. 4.-Tomograph showing malignant abscess with nodulation of the internal contour. The lesion was in the right posterior basal segment. Bronchoscopy showed an irregular tumour on the right basal carina. Histology showed epidermoid carcinoma. 


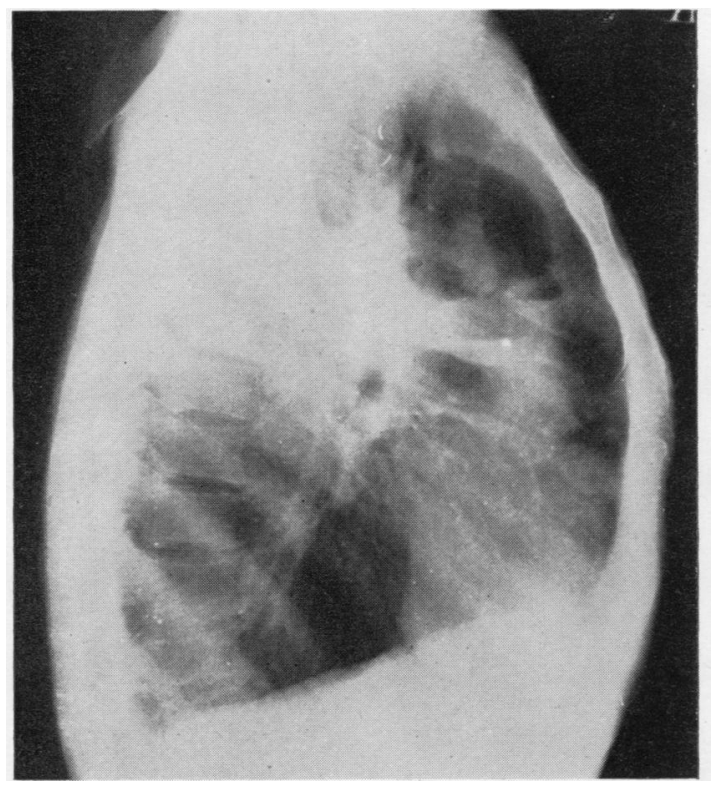

Fio. 5.

Fig. 5.-Right lateral radiograph showing abscess in the right upper lobe containing two fluid levels. The patient's main complaint was loss of weight. Bronchoscopy showed distortion, narrowing, and rigidity of right upper lobe orifice. Biopsy of a skin nodule showed epidermoid carcinoma.

Fig. 6.-Tomograph showing a large abscess $7 \mathrm{~cm} . \times 9 \mathrm{~cm}$. with characteristic irregularity of the inner wall. The patient's symptoms started with febrile illness. Bronchoscopy showed mucosal swelling at the lingular orifice, and biopsy proved it to be epidermoid carcinoma.

FIG. 7.-Radiograph showing malignant abscess in axillary segments of the left upper lobe. The patient developed cough followed by haemoptysis and pain in the chest. Bronchoscopy was normal. Left pneumonectomy was performed.

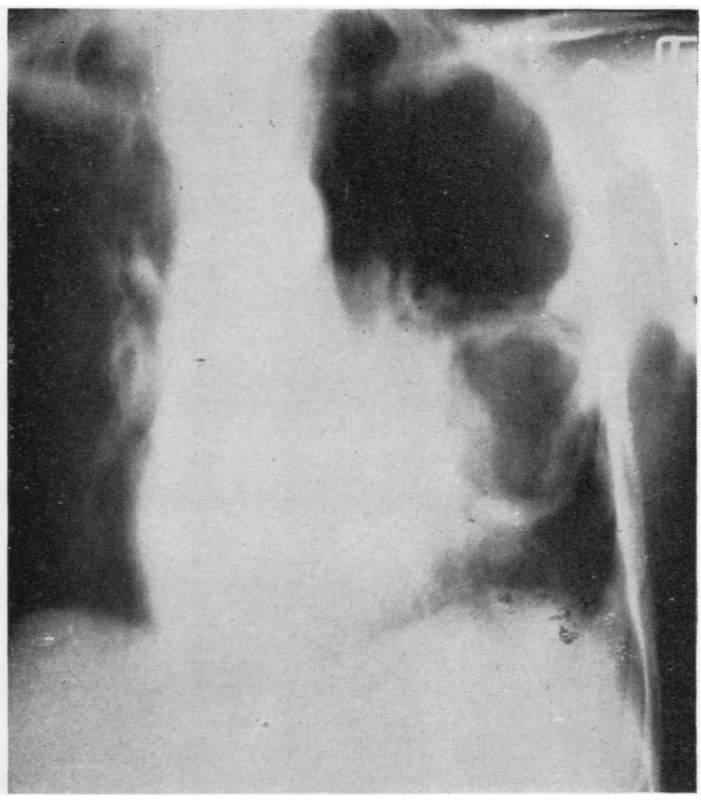

Fio. 6.

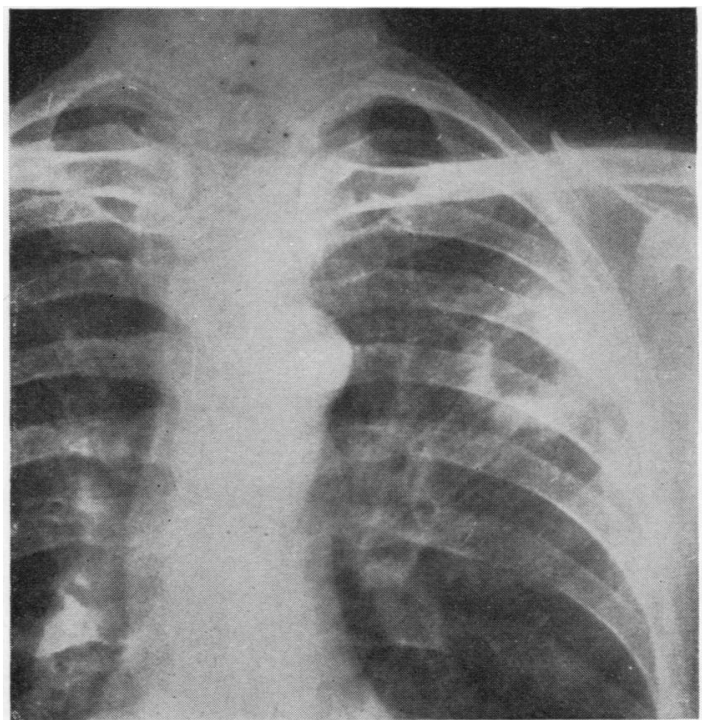

Fig. 7. 
FIG. 8 (a)-Radiograph showing atscess in the lingula with surrounding pneumonitis. The initial complaint $w$ as pain in the chest. Bronchoscopy was normal. At thoracotomy mediastinal nodes invaded by epidermoid carcinoma were seen.

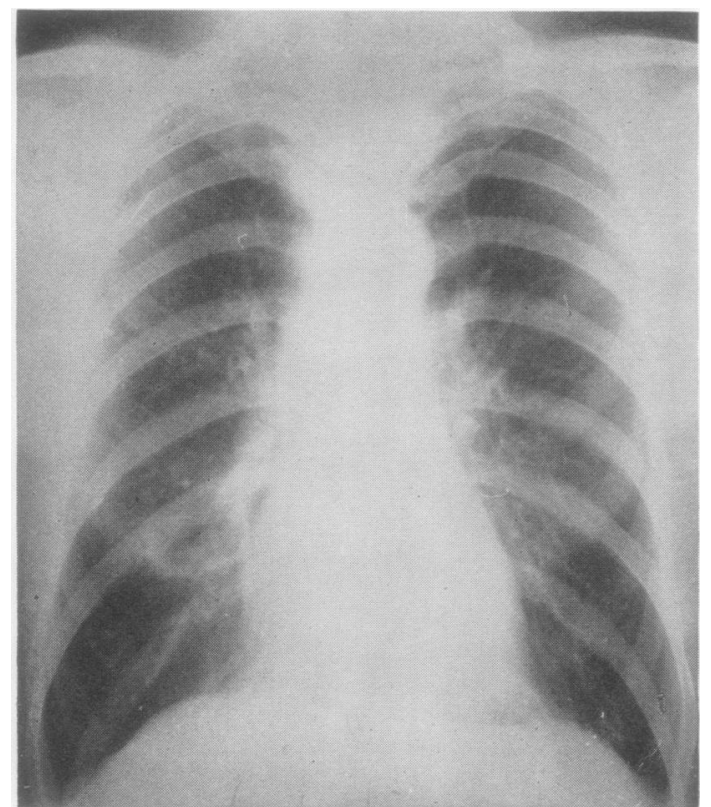

FIG. 9.-Radiograph showing cystic lesion in the apical segment of the right lower lobe. The initial complaint was haemoptysis. Epidermoid carcinoma was found after resection.

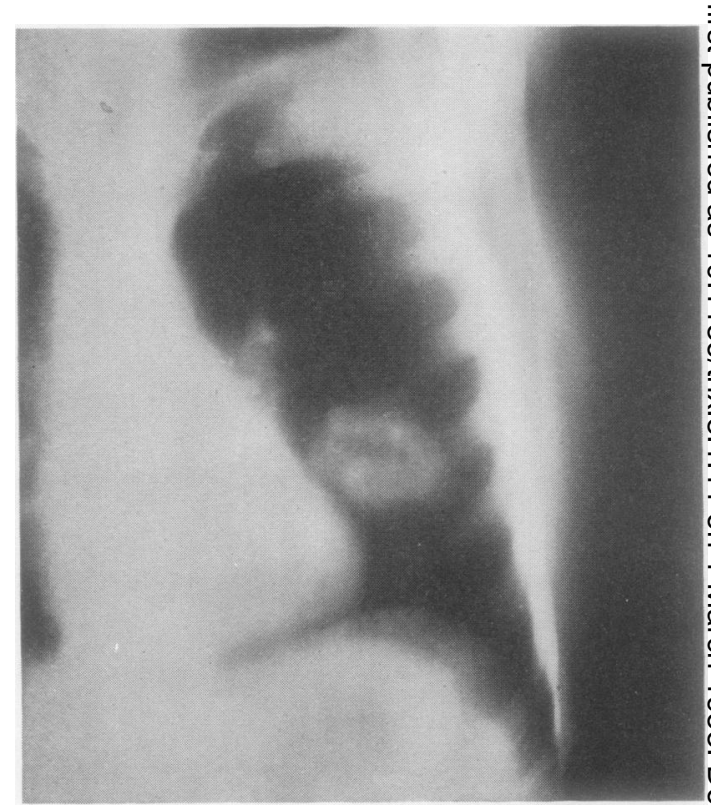

FIG. 8 (b).-Tomograph of the same lesion showing thickness of the wall.

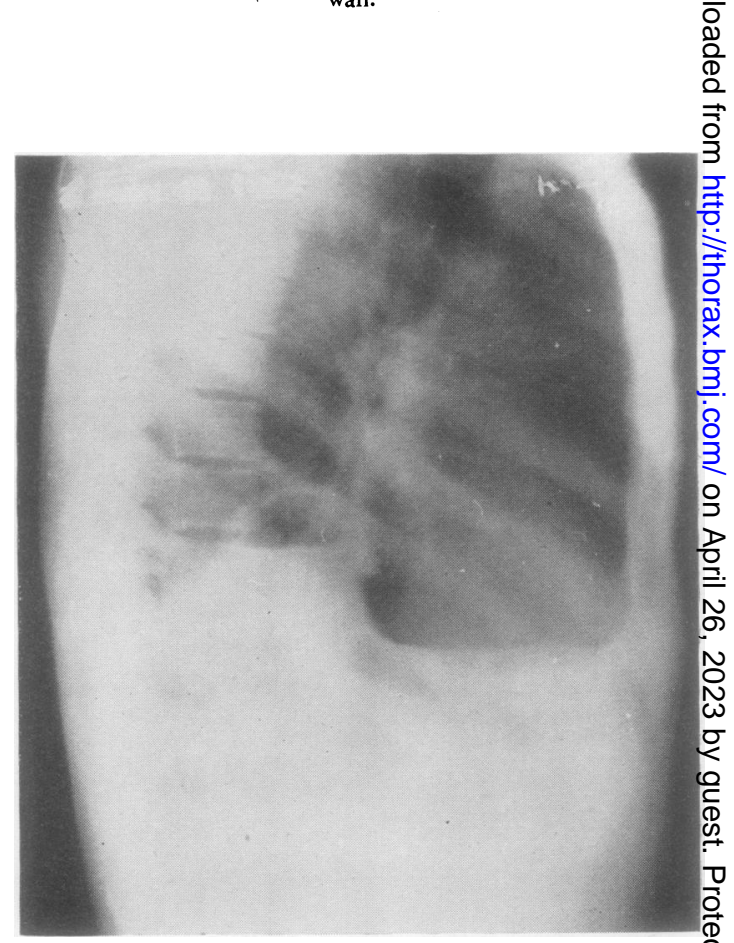

FIG. 10.-Right lateral radiograph showing collapsed right lowe? lobe with an abscess near the hilum. Bronchoscopy showed and irregularity in the right posterior basal bronchus, and biopsy an epidermoid carcinoma. 
Fig. 11.-Right lateral radiograph of a woman showing thin-walled abscess $11 \mathrm{~cm} . \times 9 \mathrm{~cm}$. in the right upper lobe. Bronchoscopy showed two nodules in the right upper lobe orifice, and biopsy epidermoid carcinoma. At thoracotomy the growth was seen to be invading the chest wall.

Fig. 12 (a).-Radiograph showing malignant abscess in the left lower lobe. The patient's main complaint was haemoptysis. Bronchoscopy showed narrowing of the left lower lobe bronchus.

Fig. 12 (b).-Left lateral view of the same lesion showirg the presence of atelectasis.

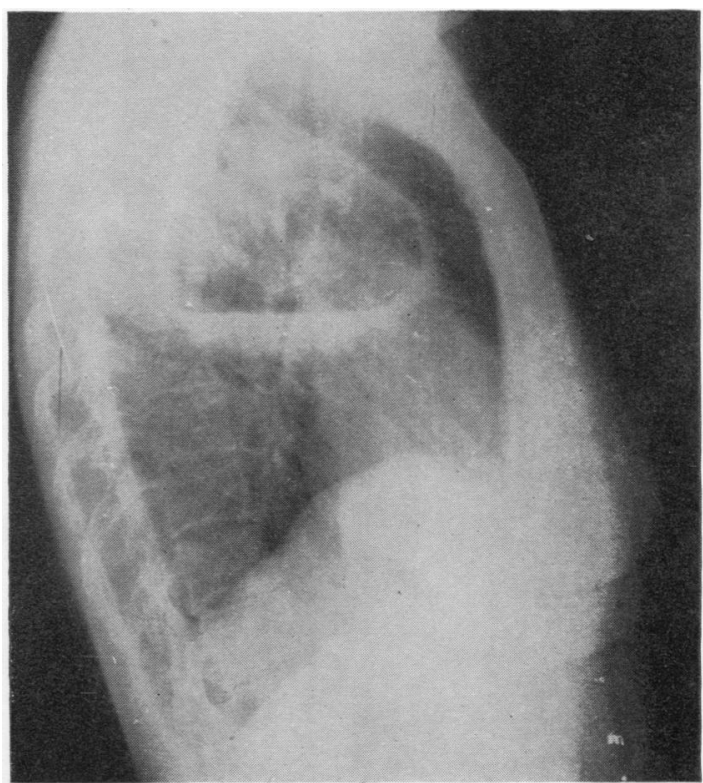

Fic. 11

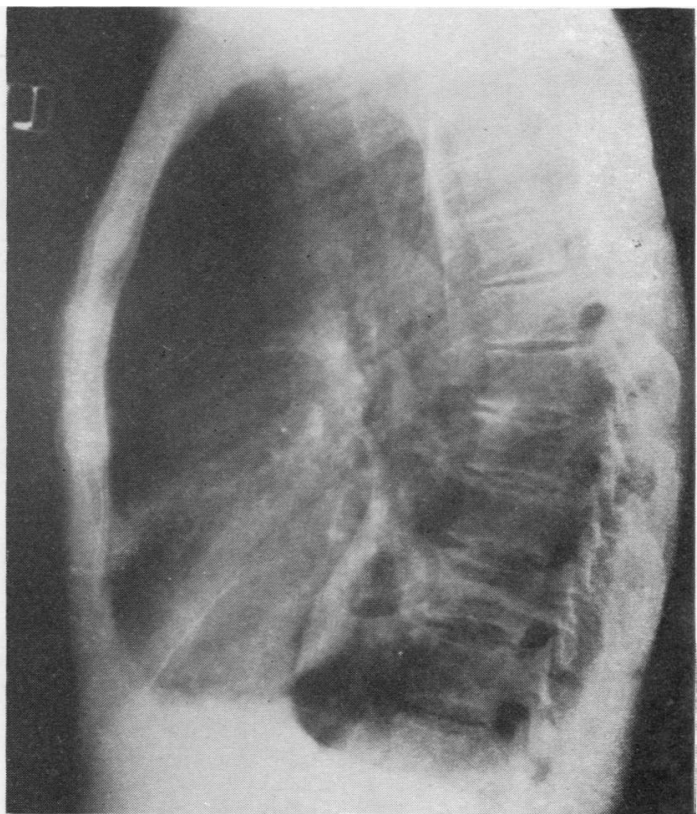

Fig. 12 (b). 
FIG. 13.-Radiograph showing neoplastic abscess $7 \mathrm{~cm} . \times 6 \mathrm{~cm}$. in the anterior segment of the left upper lobe. There was a brief history beginning with influenza. Bronchoscopy was normal.

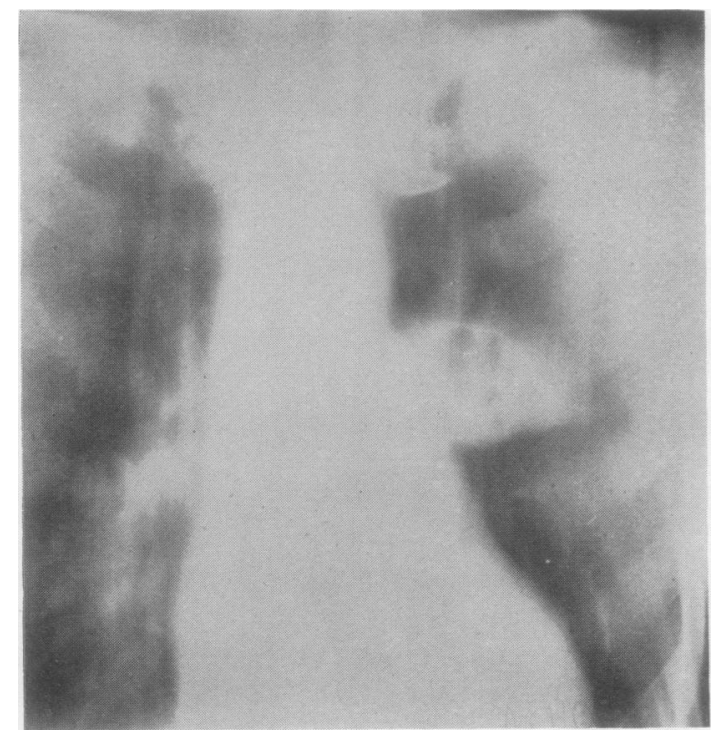

FIG. 15 (a).-Tomograph showing dense-walled abscess near the hilum. Bronchoscopy was normal. A hard mass was felt in the anterior segment of the left upper lobe at thoracotomy and pneumonectomy was performed.

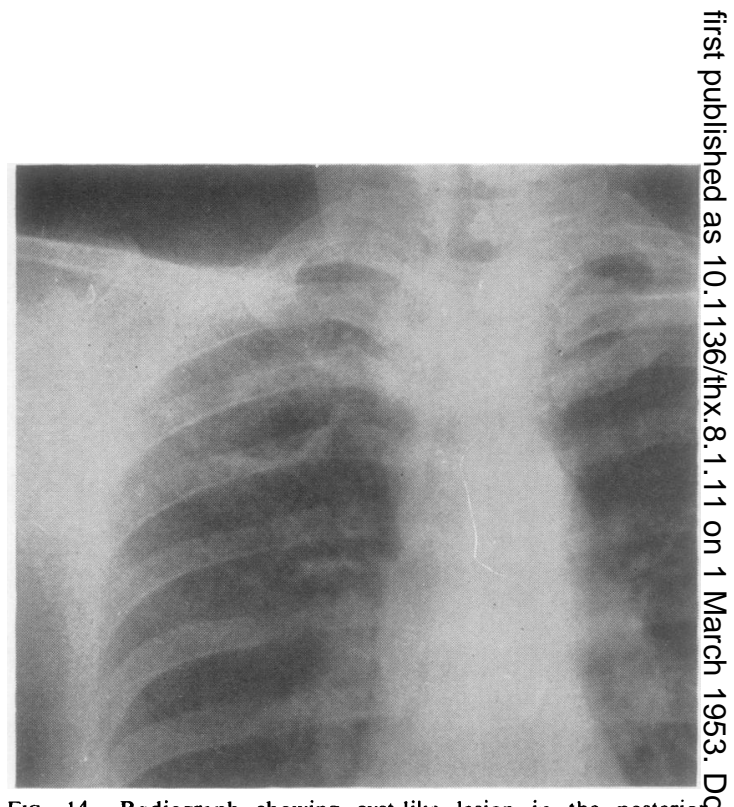

FIG. 14.-Radiograph showing cyst-like lesion in the posterion segment of the right upper iobe. Symptoms followed pneumonia and were thought to be of tuberculosis. Epidermoid carcinoma? was diagnosed after resection.

FIG. 15 (b).-Left lateral tomograph showing the same lesion. 
FIG. 16.-Radiograph showing two abscesses in the left upper lobe. The patient complained of haemoptysis following bronchitis. Bronchoscopy was normal. Thoracotomy showed a hard mass in the anterior segment of the left upper lobe and invasion of mediastina! nodes.

FIG. 17 (a) - Radiograph showing dense opacity in the right lung with irregular cavity. The patient complained of severe chest pain. Bronchoscopy showed stenosed, hard right upper lobe orifice, and biopsy an epidermoid carcinoma.

FIG. 17 (b).-Right lateral view of the same lesion.

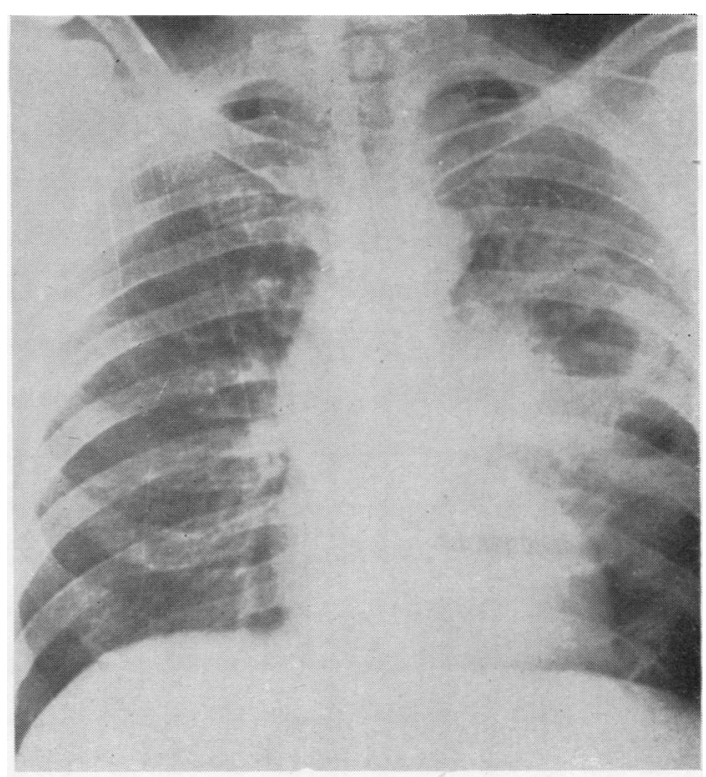

Fig. 16.

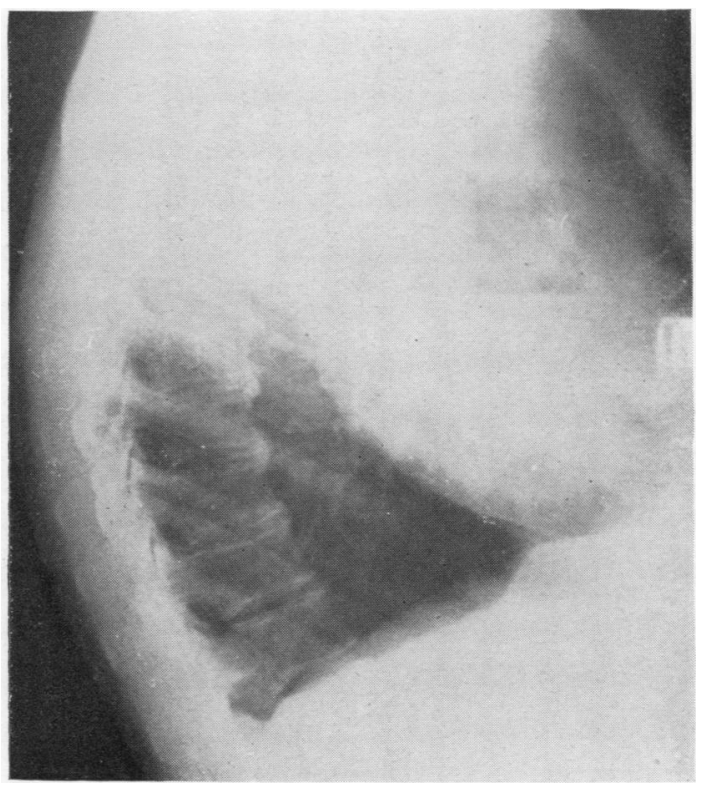

FIG. 17 (b). 


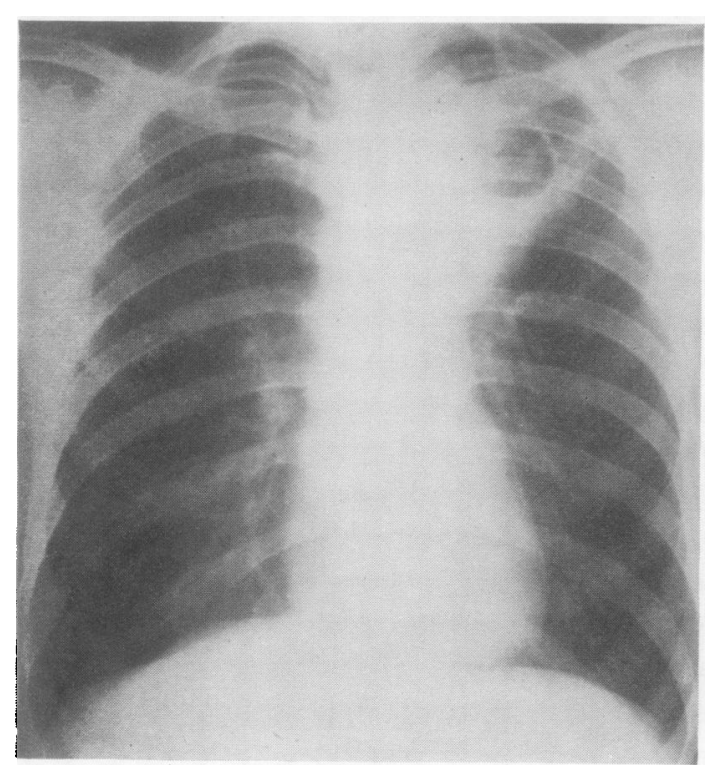

FIG. 18

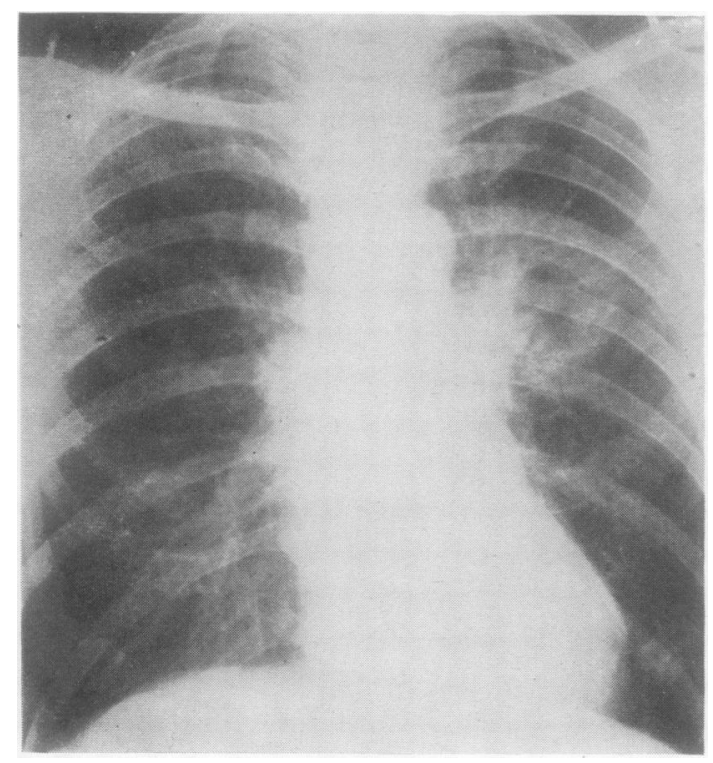

Fig. 20. 


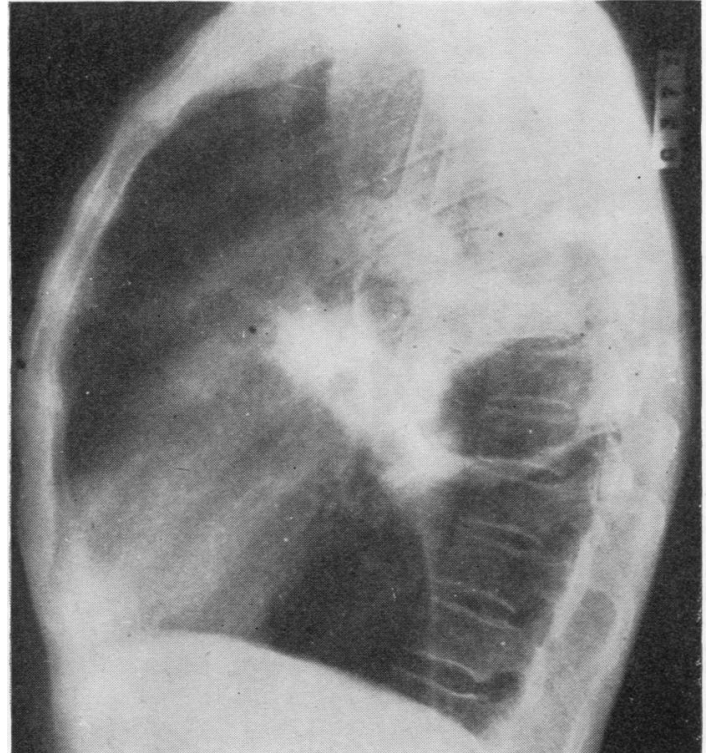

FIG. 21 (a).-Right lateral radiograph showing a large abscess $10 \mathrm{~cm} . \times 9 \mathrm{~cm}$. in the apical segment of the right lower lobe Bronchoscopy was normal. Metastases were present in the skull and brain.

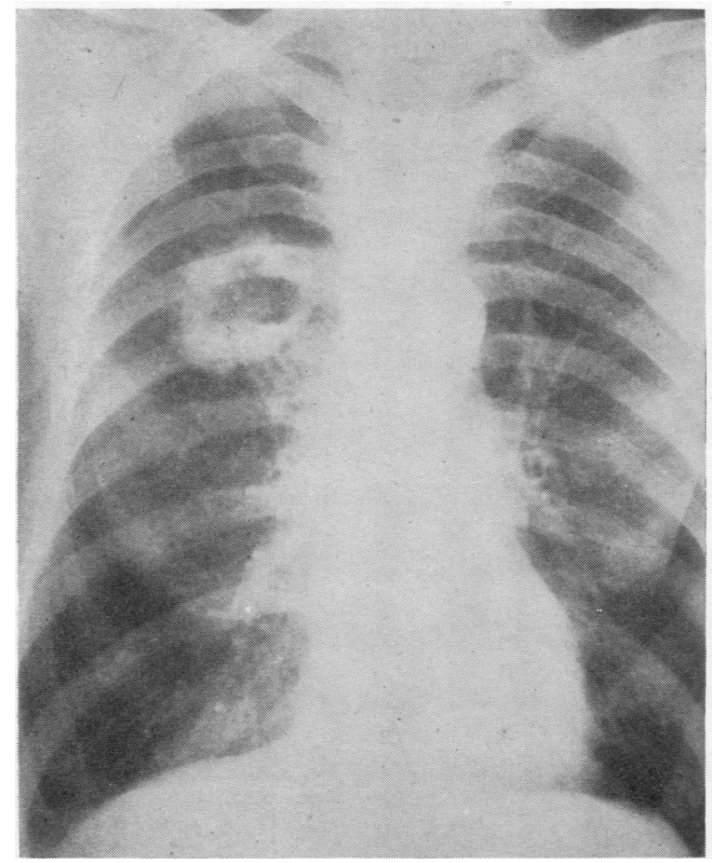

FIG. 22 (a).-Radiograph showing dense round shadow with eccentric cavitation. The symptoms of gradually increasing cough and sputum were of two years' duration. Bronchoscopy showed slight reddening in the right upper lobe. Right pneumonectomy was performed.

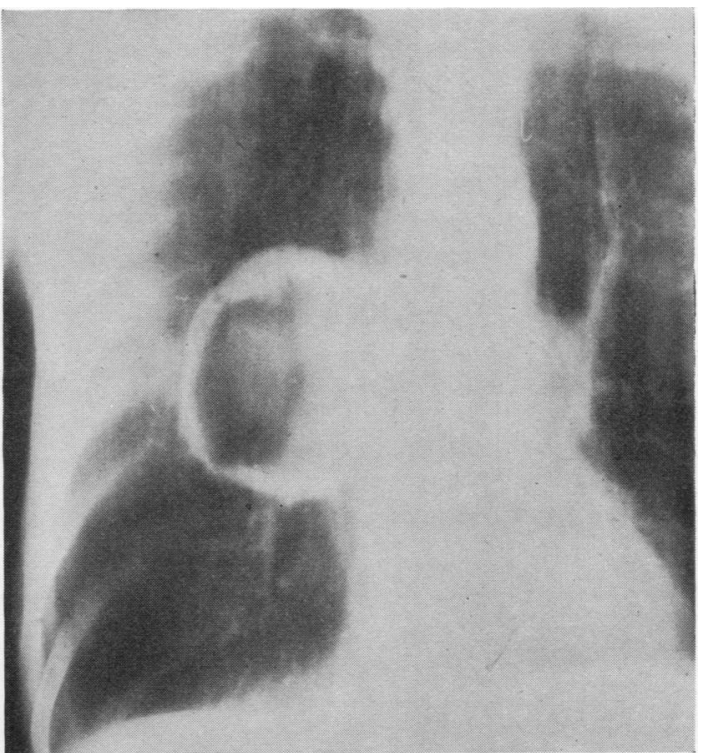

Fig. 21 (b).-Tomograph of the same lesion showing the irregular wal! of the cavity.

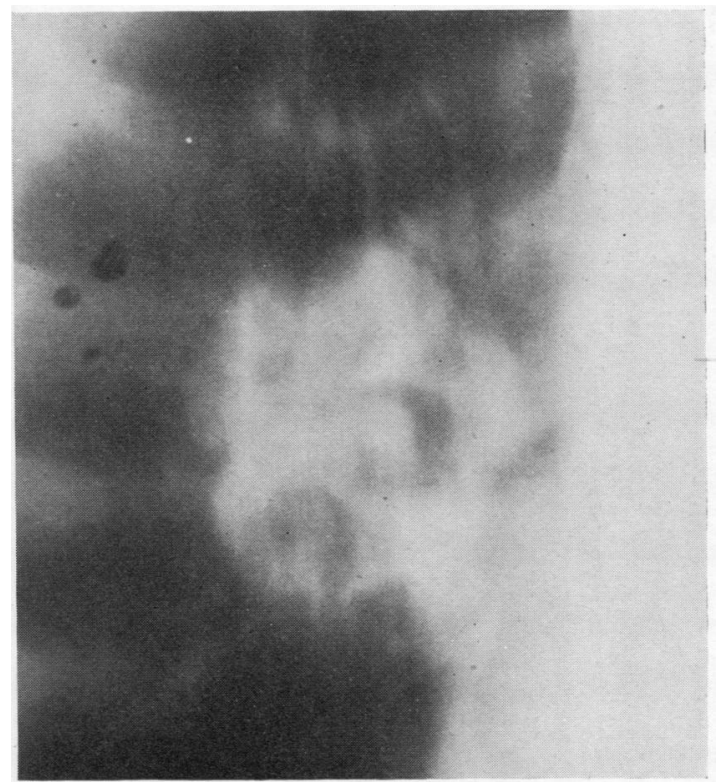

Fig. 22 (b).-Tomograph of the same lesion showing spiky projections into the cavity connected by fine strands of tissue. 
initial symptom or during the course of the disease. Finger clubbing was slightly commoner in the Type 1 cases $(70 \%$ as compared with $51 \%$ in Type 2 ), but in fact there were few differences and certainly no combination of symptoms and signs peculiar to one type.

\section{Radiological Findings}

The diagnosis of neoplastic abscess depends primarily on the radiological appearance, so that good postero-anterior and lateral radiographs are essential. Contours of the lesion not always demonstrated by the standard technique may be revealed by a penetrating Bucky view or particularly by tomographs.

The site of the abscess in these 70 cases is shown in Table V.

TABLE $\mathrm{V}$

\begin{tabular}{|c|c|c|c|}
\hline \multirow{2}{*}{\multicolumn{3}{|c|}{$\begin{array}{l}\text { SITE OF LESION IN } 70 \text { CASES OF } \\
\text { LUNG ABSCESS }\end{array}$}} & \\
\hline & & & No. of Cases \\
\hline $\begin{array}{l}\text { Left upper lobe } \\
\text {., lower ," }\end{array}$ & $\begin{array}{l}\cdots \\
\cdots\end{array}$ & $\begin{array}{l}\cdots \\
\cdots\end{array}$ & $\left.\begin{array}{l}22 \\
10\end{array}\right\} 32$ \\
\hline $\begin{array}{l}\text { Right upper lobe } \\
,, \quad \text { middle and } \\
,, \quad \text { lower lobe }\end{array}$ & $\begin{array}{c}\ldots \\
\ldots \\
\text { lower lobes } \\
\ldots\end{array}$ & $\begin{array}{l}\cdots \\
\cdots \\
\cdots \\
\therefore\end{array}$ & $\left.\begin{array}{r}22 \\
1 \\
1 \\
14\end{array}\right\} 38$ \\
\hline & Total & . & 70 \\
\hline
\end{tabular}

It will be seen that the upper lobes of both lungs are most frequently involved $(63 \%)$, and it is understandable that some of these cases were mistakenly diagnosed as tuberculous in the early stages. In some cases the lesion occupied the greater part of a lobe. Lateral films were not available in all cases, but in 50 of the 70 cases it was possible to state which pulmonary segment was involved, and this is shown in Table VI.

TABLE VI

SITE OF LESION IN TERMS OF PULMONARY SEGMENTS IN 50 CASES

\begin{tabular}{|c|c|c|c|c|c|}
\hline \multicolumn{5}{|c|}{ Site of Lesions } & No. of Cases \\
\hline \multicolumn{6}{|l|}{ Left upper lobe } \\
\hline Posterior segment & . & . & . & $\ldots$ & 7 \\
\hline Anterior segment & . & . . & . & & 5 \\
\hline Axillary branches of ante & an & osterio & $\operatorname{seg}$ & nts & 3 \\
\hline Lingula $\quad \ldots \quad \ldots$ & . & $\ldots$ & . & . & 3 \\
\hline \multicolumn{6}{|l|}{ Left lower lobe } \\
\hline Apical segment & . & r & . & . & 5 \\
\hline Posterior basal segment & . & . & . & . & 2 \\
\hline \multicolumn{6}{|l|}{ Right upper lobe } \\
\hline Posterior segment & . & . & . & . & 9 \\
\hline Anterior segment & $\ldots$ & $\ldots$ & . & & 3 \\
\hline Axillary branches of ante & an & osterio & & ents & 1 \\
\hline \multicolumn{6}{|c|}{ Right lower lobe } \\
\hline \multirow{3}{*}{$\begin{array}{l}\text { A pical segment } \\
\text { Posterior basal segment }\end{array}$} & $\ldots$ & $\ldots$ & . & .. & 10 \\
\hline & . & . & $\cdots$ & . & 2 \\
\hline & & Total & . & . & 50 \\
\hline
\end{tabular}

The segments most frequently affected were the posterior segments of the upper lobes and the apical segments of the lower lobes. These areas of the lung are also common sites for tuber- $\vec{F}$ culosis and simple lung abscess, and confusion in a few cases was caused on this account.

The abscesses varied very much in appearance. Quite often they were very large, and some of $\frac{\bar{\sigma}}{\vec{\sigma}}$ them occupied the greater part of a whole lobe $\triangle$ and could aptly be described as giant cavities. \& The cavity may enlarge quite rapidly, and in one $\overrightarrow{0}$ case this phenomenon was mistakenly regarded as ballooning of a tuberculous cavity. In 26 cases the abscess was greater than $7 \mathrm{~cm}$. in either the vertical or horizontal diameter as measured in the postero-anterior or lateral film. For the purpose of description we have divided the cases into six groups based on the radiological appearances. viz., abscesses with thick irregular walls, round opacities with central or eccentric cavitation, solid lobes containing a cavity, cyst-like cavities, abscesses with surrounding pneumonitis, and abscesses in a dense, irregular opacity.

(1) Abscesses with Thick Irregular Wall.The appearance most commonly encountered is that of a cavity in the lung substance with a dense wall which is sharply defined from the normal appearing lung tissue which surrounds it. The wall is usually thick, but its diameter is irregular, so that it may be quite thin in one aspect but thick in another. In some cases the wall of the abscess is quite thin and regular, but in one part of its contour it shows a marked internal bulge. Perhaps the most characteristic appearance of a carcinomatous abscess is nodulation of the internal contour, and antero-posterior and lateral tomographs are particularly valuable in demonstrating this sign. Sometimes only one nodule is apparent and in a few cases there were spiky projections from the internal contour. The abscess is rounded or oval and one or more fluid levels are usually present.

The density and thickness of the abscess wall are by no means characteristic of carcinoma, however. The wall of a simple lung abscess is usually thin. N but in some cases it is just as thick as in the malignant case. In the 30 cases of simple abscess 0 studied for comparison, a thick, dense wall was $\mathfrak{\omega}$ seen in seven cases, but in only one of these was? the internal contour of the abscess wall markedly $Q$ irregular. Whereas most of the malignant abscesses of this type had a sharply outlined outer $\stackrel{?}{\rightarrow}$ $u$ all, the simple abscesses were usually surrounded 0 by a diffuse opacity shading into normal lung tissue. This characteristic appearance of a thick. irregular abscess wall sharply demarcated from $\mathbb{Q}$ normal lung tissue was seen in 27 cases. Most of these were undoubtedly examples of breaking- 
down peripheral carcinomas, but in six cases endobronchial growth was seen at bronchoscopy, and a positive biopsy was obtained in five of these. A diffuse opacity surrounding the abscess or "pneumonitis" was seen in only seven cases, whereas it was present in more than half the cases (17 out of 30 ) of simple lung abscess.

(2) Round Opacity with Central or ECCENTRIC CAVitation.-In 10 cases the appearance was that of a dense, round shadow in the lung showing a central or eccentric area of cavitation. In nine of these cases there were normal bronchoscopic findings. This appearance probably represents an early stage of central necrosis in a peripheral type of carcinoma, for it is the dense, round shadow rather than the abscess which is the striking feature. The average diameter of these round shadows was $6 \mathrm{~cm}$., the smallest lesion being $4 \mathrm{~cm} . \times 4 \mathrm{~cm}$. and the largest $12 \mathrm{~cm} . \times 10 \mathrm{~cm}$. In four of the cases the cavitation was quite eccentric, a feature which Brock (1948a) considers highly suggestive of neoplasm. Several of these cases showed nodular projections of growth into the cavity, and in two cases these projections were joined to each other by irregular bands of tissue running across the cavity. A fluid level was showing in five cases.

A solid, round opacity cavitated in four cases while they were under observation, and two of these are included in this group. The development of cavitation in a previously solid focus is very suggestive of a primary lung cancer, as metastatic neoplasms only rarely break down. A hydatid cyst may produce a similar appearance when partial rupture occurs and some of its contents leak into the bronchial tree, and may be responsible for occasional difficulty in diagnosis.

Probably the most difficult problem is to distinguish this type of lesion from a solid tuberculous focus or tuberculoma which is beginning to break down. The majority of tuberculomas are smaller than these cavitating neop'asms and they tend to occur in a younger age group, but the differentiation is often very difficult, and many have been removed because of genuine uncertainty about their nature. Careful radiography and the use of tomography may show areas of satellite shadowing or infiltration elsewhere in the lungs which is suggestive of tuberculosis, and if calcification in the lesion can be demonstrated it is virtually diagnostic of this disease. Moyes (1951) points out that neither hilar adenopathy nor increase in the size of the lesion on serial radiography is a proof of neoplasm, as the former may be associated with primary tuberculosis, and enlargement of a tuberculoma is fairly commonly seen. Repeated examination of the sputum, or, if necessary, gastric juice for tubercle bacilli with liberal use of cultures or animal inoculation, may give a positive result which will settle the diagnosis. It should always be remembered in this connexion that in rare cases bronchial carcinoma and tuberculosis may be present in the same patient.

(3) Solid Lobe Containing a Cavity.-Thirteen cases showed a solid lobe containing a fluid level or a central translucency. In nine of the cases the uniform dense opacity was due to collapse of the affected lobe; the other four were examples of clearly defined lobar consolidation. All but one of these cases showed a fluid level with a clear area of translucency above it. The presence of air in the cavity sufficed to outline the inner wall of the abscess, and, as in the previous groups, this was often seen to be irregular and show projecting spikes or nodules. Bronchoscopic evidence of a carcinoma arising in a major bronchus was obtained in eight of the cases. In the five cases with negative findings, two of the growths were situated in an upper lobe, and two were in the apical segment of a lower lobe and so may have been beyond the reach of endoscopic vision. The majority of cases in this group thus arose as abscesses distal to a neoplastic bronchial obstruction.

(4) Thin-walled Cavity Like a Cyst.-In four cases the cavity wall was very thin and the abscess had a cystic appearance. These cases were most difficult to diagnose, and for a time each was considered to be either tuberculous or an infected congenital cyst of the lung. In two of the cases serial films showed cavity distension, and with the surrounding infiltration they mimicked the appearance of tubercle very closely. Three of the patients had actually been admitted to sanatoria in the early stages of their illness, but a positive sputum was never obtained. The difficulty in diagnosis may be illustrated by the following case :

Case 4 (No. 7337).-A man aged 38 had a brisk haemoptysis in August, 1949. A mass miniature radiograph taken at that time was negative, so after a few days he returned to work. He remained in excellent health until a year later, when the bloodspitting recurred. He then developed a cough productive of a small quantity of clear sputum and began to feel tired and short of breath on exertion. Frequent small haemoptyses occurred at intervals. Radiographs taken at this time showed a thin-walled cavity in the apical segment of the right lower lobe which was regarded as probably tuberculous. He was 
admitted to hospital, where the sputum was examined repeatedly for tubercle bacilli, but always with negative results. A course of streptomycin and paraaminosalicylic acid (P.A.S.) failed to produce any radiographic improvement, and in fact the cavity became larger, though by now the haemoptysis had ceased. On May 2, 1951, he was transferred to Shotley Bridge Hospital for further investigation. Examination showed a healthy-looking man; the temperature was normal, the blood count normal, and the B.S.R. $6 \mathrm{~mm}$. in one hour (Westergren). Radiographs showed a thin-walled cavity with no surrounding infiltration in the apical segment of the right lower lobe. Tomograms merely confirmed that the wall of the cavity was thin and smooth; there was no fluid level. A bronchoscopy was normal, and examination of the sputum for tubercle bacilli confirmed the previous negative findings. A bronchogram was then performed, and this showed a block in the bronchus to the apical segment of the right lower lobe and failure of this segment to fill. It was felt, nevertheless, that the lesion was probably a tuberculous cavity or an infected congenital cyst, and it was decided to carry out a segmental resection. On May 1, 1951, a resection of the apical and subapical segments of the right lower lobe was performed. The specimen showed a distension type of cavity with a smooth wall and a carcinoma arising in the bronchus to the apical segment, causing almost total bronchial obstruction. Histological examination of the endobronchial growth and of the cavity wall showed an epidermoid carcinoma. Ten days later the chest was again opened and a right pneumonectomy was performed. The patient survived the post-operative period and was well when discharged, but it is too early yet to assess the result.

(5) Abscess with Surrounding Pneumonitis. -These cases, of which there were seven, resembled many of the cases of simple lung abscess in that they were surrounded by an area of pneumonitis. Some of these were thick-walled abscesses, showing all the features of the cases described in the first group, except that the outer wall was not discrete; others were thin-walled, and showed as an area of translucency in the midst of a diffuse opacity.

(6) Abscess in Dense, Irregular Opacity.There were nine cases in which the cavitation occurred in the middle of a dense, irregular opacity. These cases looked like infiltrating bronchial carcinomas and did not present any real problem in diagnosis.

In addition to the appearances described in these groups there were several other features which were of assistance in diagnosis. For instance, there was evidence of atelectasis in 15 cases: Nine of these have already been described in Group 3 (solid lobe containing cavity), but in the other six collapse was present as well as a round opacity, a cyst-like cavity, or a dense, irregular mass. Erosion of ribs was demonstrated radiologically in three cases. The marked tendency of this type of tumour to spread locally has already been mentioned, and in a further eight cases invasion of the chest wall was seen at thoracotomy. The tumour was situated in an upper lobe in eight of these 11 cases, and in the apical segment of a lower lobe in the other three. Enlargement of the paratracheal or hilar lymph nodes was seen in the radiographs of six cases.

In the absence of a readily absorbable contrast medium, bronchography has played a limited part in the diagnosis of our cases of bronchial carcinoma and was used in only four cases of this series. In three of these the abscess was situated in the apical segment of a lower lobe and obstruction to filling of this segment was demonstrated. The other showed a bronchial block at the margin of a peripheral shadow.

Examination of the radiographs of the 27 patients in whom bronchoscopy showed evidence of a carcinoma involving a major bronchus (Type 1) indicated that the majority of the abscesses arose as the result of bronchial obstruction, but in eight cases the appearances suggested that cavitation was taking place in tumour tissue itself.

\section{RESULTS}

The majority of these patients, when admitted to hospital, were found to be beyond the reach of radical surgery because of the extent of the growth, metastases, advanced age, or poor general condition. Five patients refused an operation. The results of those treated are shown in Tables VII and VIII.

Open drainage was performed as a palliative measure in four cases, but in only one was there marked symptomatic benefit. Two cases were treated as chronic lung abscesses, the diagnosis of malignancy being established by biopsy of the cavity wall.

In addition to the cases listed in these tables, 15 had a thoracotomy without resection of lung tissue. The cases were inoperable owing to invasion of the chest wall (seven cases), invasion of the mediastinum, pericardium, or great vessels $\mathbb{D}$ (seven cases), and the presence of malignant? nodules in the pleura and diaphragm (one case).

Deep radiotherapy was administered to 16 patients (one of whom also had a lobectomy and one an open drainage of the abscess). Thirteen of these are dead or presumed dead. The date of death is known in 11 cases, but in two cases 
TABLE VII

RESULTS OF PNEUMONECTOMY IN 13 CASES

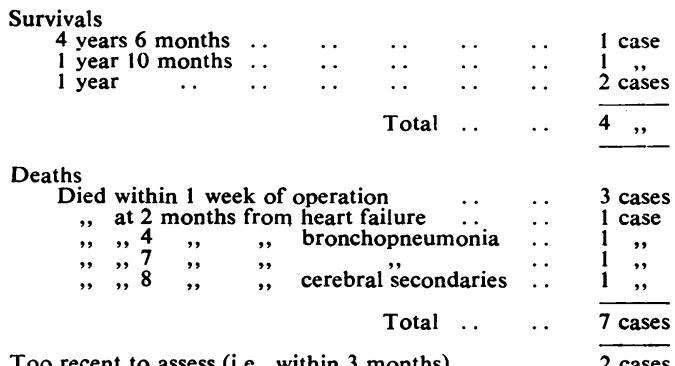

TABLE VIII

RESULTS OF LOBECTOMY IN FOUR CASES

Died 1 day after operation. (Necropsy, coronary

Died 1 month later; lobar pneumonia opposite lung

Returned with metastases 6 months later.

Died 21 months later with widespread metastases

$$
\text { Total }
$$

RESULTS OF OPEN DRAINAGE IN SıX CASES

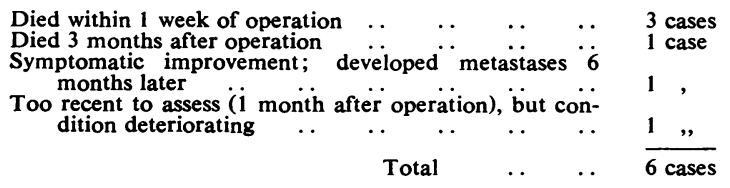

treated during the war years the final result was not ascertained, though both were known to develop metastases (one rib, one neck glands) within four months of starting treatment. The average period of survival in the 11 patients in whom the date of death is known was 5.7 months from the time of starting treatment. The longest period of survival was 18 months. Three patients are still alive and have survived 12 months, two months, and one month respectively. The symptomatic benefit obtained from therapy was unimpressive. A few showed slight clinical improvement, but an equal number deteriorated rapidly when therapy was started. Radiologically, two cases showed a diminution in the opacity, but in three cases the area of cavitation steadily increased.

No specific treatment was given in 33 cases. Twenty-eight are known to be dead and the date of death was obtained in 26 of them. The average period of survival in these cases was four months from the time of diagnosis and the longest survival was 13 months. Of the surviving five cases, three have been in hospital within the last four months and their fate is as yet unknown. One has survived five and the other eight months, but both are now deteriorating rapidly.

\section{Discussion}

The majority of articles on lung abscess deliberately exclude cases of bronchial carcinoma from the study. As the prognosis and treatment are those of the malignant disease rather than the abscess, this is quite reasonable, but it has resulted in a lack of appreciation of the frequent coexistence of these conditions. As Brock (1948b) has emphasized, the most important step in making a diagnosis of carcinoma is to think of it, and this particularly applies in a condition like lung abscess when the evidence of malignancy may be masked. Although many of these cases may be recognized as neoplastic, there remain a certain number in whom the clinical and radiological findings closely resemble a benign inflammatory condition. A lung abscess occurring in a patient over 40, especially if its onset is insidious and the response to postural drainage and antibiotic therapy slow, should be considered as probably malignant and full investigation hurried forward. The examination of the sputum for cancer cells was unfortunately not available in any of the cases in this series. The methods of Dudgeon or Papanicolaou are reported to give a high percentage of positive results in the sputum, and even better results are recorded by Herbut and Clerf (1946) and Gibbon, Clerf, Herbut, and DeTuerk (1948) on the cytological study of secretions removed at bronchoscopy. The technique of endoscopic sponge biopsy as described by Carter, Nesbit, and Piper (1951) also seems promising in differentiating inflammatory disease from carcinoma. Although we have no direct experience of such investigations, they seem likely to be of great value in the diagnosis of these cases where the bronchoscopic examination itself is so often negative. Thoracotomy should not be unduly delayed, although even when the lung can be palpated the diagnosis may be difficult to make with certainty. The examination of operative biopsies by the frozen section technique confirmed the diagnosis in two cases and might usefully be employed more often.

\section{SUMMARY}

This study is based on a series of 70 cases of neoplastic lung abscess. The incidence of cavitation, evident on radiological examination, was found to be $3.6 \%$ in 1,930 cases of bronchial carcinoma.

The pathology of the lesion is discussed. Histological examination of the tumour was carried out in 44 cases ; 36 of these were found to be of the squamous cell type. 
The clinical picture is described with particular attention to the initial manifestations of the disease, and comparison is made with the clinical findings in a group of cases with simple lung abscess.

Bronchoscopy was performed in all the cases, and on the basis of the findings the cases were divided into two types. Type 1 were cases in which a carcinoma involved a major bronchus with distal abscesses. In Type 2 the findings were essentially negative, and in these cases the abscess appeared to arise by necrosis in a tumour mass.

- The radiological appearances are described, the cases being considered in six groups. The resemblance of the lesion to other conditions such as chronic lung abscess, pulmonary tuberculosis, and simple lung cyst is discussed and points in the differentiation from these conditions are described.

The prognosis of the condition is very poor. Pneumonectomy was performed in 13 cases, four of which are surviving one year or more after operation. Lobectomy was performed in four cases, but there are no survivors. The results of deep $x$-ray therapy were poor. There was no evidence that it prolonged life, and only a few cases exhibited symptomatic improvement.

Our thanks are due to Mr. George A. Mason for access to the clinical records of these cases and for his encouragement in the preparation of this paper ; also to Dr. Whately Davidson for his co-operation in the investigation of the cases and his help in the interpretation of the radiographs.

\section{REFERENCES}

Arkin, A., and Wagner, D. H. (1936). J. Amer. med. Ass., 106, 587. Brock, R.'C. (1948a). Guy's Hosp. Rep., 97, 75.

- (1948b). Brit. med.J., 2, 737.

Carter, M. G., Nesbit, R. R., and Piper, C. A. (1951). J. thorac. Surg., 22, 386

Davidson, S. W. (1948). In Modern Trends in Diagnostic Radiology, ed. McLaren, J. W., ch. 9, London.

Fishberg, M., and Rubin, E. H. (1929). Amer. J. med Sci., 178, 20.
Gibbon, J. H., Clerf, L. H., Herbut, P. A., and DeTuerk, J. J. (1948). Jibbon, J. H., Clerf, L. H., Her. Surg., 17, 419.
thor.

Goldman, A. (1942). J. Amer. med. Ass., 118, 359

Gray, H. K., Fryfogle, J. D., and Good, C. A. (1951). Surg. Clin. N. Amer., 31, 1199

Herbut, P. A., and Clerf, L. H. (1946). Med. Clin. N. Amer., 30, 1384

Jaffé, R H (1935) J Lab clin. Med 20.1227.

Jaffe, R. H. (1935). J. Lab. clin. Med., 20, 1227.

Koletsky, S. (1938). Arch. intern. Med., 62,

Maxwell, (1934). Quart. J. Med., 3, 467.

Moyes, E. N. (1951). Thorax, 6, 238

Olds, J. W., and Kirklin, B. R. (1940). Amer. J. Roentgenoi., 44, 357 Strang, C. (1949). " "Bronchial Carcinoma." M.D. thesis, Durham University.

Sutherland, A. W., and Grant, L. J. (1950). Lancet, 1, 530. 